\title{
Evaluation of stress tolerance and fermentative behavior of indigenous Saccharomyces cerevisiae
}

\author{
Cíntia Lacerda Ramos ${ }^{1}$, Whasley Ferreira Duarte ${ }^{1}$, Ana Luiza Freire ${ }^{1}$, \\ Disney Ribeiro Dias ${ }^{2}$, Elis Cristina Araújo Eleutherio ${ }^{3}$, Rosane Freitas Schwan ${ }^{1}$ \\ ${ }^{1}$ Departamento de Biologia, Universidade Federal de Lavras, Lavras, MG, Brazil. \\ ${ }^{2}$ Departamento de Ciência de Alimentos, Universidade Federal de Lavras, Lavras, MG, Brazil. \\ ${ }^{3}$ Departamento de Bioquímica, Universidade Federal do Rio de Janeiro,Rio de Janeiro, Brazil.
}

Submitted: November 2, 2012; Approved: September 10, 2012.

\begin{abstract}
Sixty six indigenous Saccharomyces cerevisiae strains were evaluated in stressful conditions (temperature, osmolarity, sulphite and ethanol tolerance) and also ability to flocculate. Eighteen strains showed tolerant characteristics to these stressful conditions, growing at $42{ }^{\circ} \mathrm{C}$, in $0.04 \%$ sulphite, 1 $\mathrm{mol} \mathrm{L}^{-1} \mathrm{NaCl}$ and $12 \%$ ethanol. No flocculent characteristics were observed. These strains were evaluated according to their fermentative performance in sugar cane juice. The conversion factors of substrates into ethanol $\left(Y_{\mathrm{p} / \mathrm{s}}\right)$, glycerol $\left(Y_{\mathrm{g} / \mathrm{s}}\right)$ and acetic acid $\left(Y_{\mathrm{ac} / \mathrm{s}}\right)$, were calculated. The highest values of $Y_{\mathrm{p} / \mathrm{s}}$ in sugar cane juice fermentation were obtained by four strains, one isolated from fruit $(0.46)$ and the others from sugar cane $(0.45,0.44$ and 0.43$)$. These values were higher than the value obtained using traditional yeast $(0.38)$ currently employed in the Brazilian bioethanol industry. The parameters $Y_{\mathrm{g} / \mathrm{s}}$ and $Y_{\mathrm{ac} / \mathrm{s}}$ were low for all strains. The UFLA FW221 presented the higher values for parameter related to bioethanol production. Thus, it was tested in co-culture with Lactobacillus fermentum. Besides this, a 20-L vessel for five consecutive batches of fermentation was performed. This strain was genetically stable and remained viable during all batches, producing high amounts of ethanol. The UFLA FW221 isolated from fruit was suitable to produce bioethanol in sugar cane juice. Therefore, the study of the biodiversity of yeasts from different environmental can reveal strains with desired characteristics to industrial applications.
\end{abstract}

Key words: alcoholic fermentation, biofuel, fermentation kinetics, UFLA FW221, Saccharomyces cerevisiae.

\section{Introduction}

Carbon dioxide $\left(\mathrm{CO}_{2}\right)$ released from the burning of fossil fuels, such as petroleum and coal, is considered a major contributor to global warming. There is consequently a need for alternative, carbon-neutral energy sources. Bioethanol, a renewable fuel, can be considered an alternative to fossil fuel use (Cardona and Sánchez, 2007).

Ethanol production by microorganisms has received global attention because it can be obtained from renewable sources. Many new ethanol plants are being built to increase supply, and researchers are investigating ways improve the yield of ethanol production (Antoni et al., 2007).
In the United States, the most ethanol is produced from corn, while Brazil mainly produces ethanol from sugar cane (Basso et al., 2008). Sugar cane is used as a substrate, and ethanol concentrations of $8-11 \%(\mathrm{v} / \mathrm{v})$ are achieved within a period of $6-11 \mathrm{~h}$ at $30-35^{\circ} \mathrm{C}$. After fermentation, yeast cells are recycled during a production season of 200-250 days (Wheals et al., 1999).

The Brazilian bioethanol industry has grown in the last few decades as a result of the international oil crisis. Sugar cane crop productivity has increased due to genetic improvements in cultivars and ongoing research to increase the efficiency of fermentative processes (Cardona and Sánchez, 2007). Scientific and technological advances, regard-

Send correspondence to R.F. Schwan. Departamento de Biologia, Universidade Federal de Lavras, 37.200-000 Lavras, MG, Brazil. E-mail: rschwan@dbi.ufla.br. 
ing sugar cane varieties, agricultural and fermentation process management and engineering, for example, have led to an increase in the efficiency of Brazilian bioethanol distilleries. The selection of new Saccharomyces cerevisiae strains could be a suitable way to amplify fuel production on an industrial scale (Basso et al., 2008). Industrial fermentation processes impose multiple stressful conditions (e.g., temperature, ethanol concentration, osmotic pressure and ionic stress) on yeast that affect its performance and kinetics during alcoholic fermentation (Fleet, 2008). Changes in temperature are by far the most studied stress inducers in living cells (Aguilera et al., 2007; Babiker et al., 2010). Saccharomyces cerevisiae has been chosen over the centuries because it is physiologically adapted to these unfavorable conditions (Attfield, 1997). The present work proposes to study the behaviour of indigenous $S$. cerevisiae in stressful conditions and selected strains were subjected to sugar cane fermentation in order to study the associated kinetics parameters. Finally, the selected strain was tested in co-culture with Lactobacillus fermentum to simulate a contaminated fermentation and also batch fermentations in sugar cane juice on a semi-industrial scale were performed.

\section{Material and Methods}

\section{Yeast strains}

The indigenous yeast strains used in this study were isolated from bioethanol distilleries (sugar cane fermentations) and fruit wine fermentations and belong to the microbial collection of the Microbial Physiology Laboratory/Department of Biology /Federal University of Lavras (UFLA), Brazil. The strain PE-2 (commercialized in Brazil for bioethanol production) was used as a reference strain. A total of 66 yeast strains were studied (Table 1).

Table 1 - Saccharomyces cerevisiae strains studied and their respective sources.

\begin{tabular}{|c|c|c|c|}
\hline S. cerevisiae strain & Source & S. cerevisiae strain & Source \\
\hline UFLA CA751 & Distillery (UFLA/Brazil) & UFLA CA776 & Distillery (UFLA/Brazil) \\
\hline UFLA CA752 & Distillery (UFLA/Brazil) & UFLA CA777 & Distillery (UFLA/Brazil) \\
\hline UFLA CA753 & Distillery (UFLA/Brazil) & UFLA CA778 & Distillery (UFLA/Brazil) \\
\hline UFLA CA754 & Distillery (UFLA/Brazil) & UFLA CA779 & Distillery (UFLA/Brazil) \\
\hline UFLA CA755 & Distillery (UFLA/Brazil) & UFLA CA780 & Distillery (UFLA/Brazil) \\
\hline UFLA CA756 & Distillery (UFLA/Brazil) & UFLA CA781 & Distillery (UFLA/Brazil) \\
\hline UFLA CA757 & Distillery (UFLA/Brazil) & UFLA CA782 & Distillery (UFLA/Brazil) \\
\hline UFLA CA155 & Distillery (UFLA/Brazil) & UFLA CA783 & Distillery (UFLA/Brazil) \\
\hline UFLA CA758 & Distillery (UFLA/Brazil) & UFLA CA784 & Distillery (UFLA/Brazil) \\
\hline UFLA CA759 & Distillery (UFLA/Brazil) & UFLA CA785 & Distillery (UFLA/Brazil) \\
\hline UFLA CA760 & Distillery (UFLA/Brazil) & UFLA CA786 & Distillery (UFLA/Brazil) \\
\hline UFLA CA93 & Distillery (UFLA/Brazil) & UFLA CA787 & Distillery (UFLA/Brazil) \\
\hline UFLA CA761 & Distillery (UFLA/Brazil) & UFLA CA788 & Distillery (UFLA/Brazil) \\
\hline UFLA CA762 & Distillery (UFLA/Brazil) & UFLA CA789 & Distillery (UFLA/Brazil) \\
\hline UFLA CA15 & Distillery (UFLA/Brazil) & UFLA CA790 & Distillery (UFLA/Brazil) \\
\hline UFLA CA76 & Distillery (UFLA/Brazil) & UFLA CA791 & Distillery (UFLA/Brazil) \\
\hline UFLA CA116 & Distillery (UFLA/Brazil) & UFLA CA792 & Distillery (UFLA/Brazil) \\
\hline UFLA FW45 & Fruit wine (UFLA/Brazil) & UFLA CA793 & Distillery (UFLA/Brazil) \\
\hline UFLA FW221 & Fruit wine (UFLA/Brazil) & UFLA CA794 & Distillery (UFLA/Brazil) \\
\hline UFLA FW510 & Fruit wine (UFLA/Brazil) & UFLA CA795 & Distillery (UFLA/Brazil) \\
\hline UFLA CA763 & Distillery (UFLA/Brazil) & UFLA CA796 & Distillery (UFLA/Brazil) \\
\hline UFLA CA764 & Distillery (UFLA/Brazil) & UFLA CA797 & Distillery (UFLA/Brazil) \\
\hline UFLA CA765 & Distillery (UFLA/Brazil) & UFLA CA798 & Distillery (UFLA/Brazil) \\
\hline UFLA CA766 & Distillery (UFLA/Brazil) & UFLA CA799 & Distillery (UFLA/Brazil) \\
\hline UFLA CA767 & Distillery (UFLA/Brazil) & UFLA CA800 & Distillery (UFLA/Brazil) \\
\hline UFLA CA768 & Distillery (UFLA/Brazil) & UFLA CA801 & Distillery (UFLA/Brazil) \\
\hline UFLA CA769 & Distillery (UFLA/Brazil) & UFLA CA802 & Distillery (UFLA/Brazil) \\
\hline UFLA CA770 & Distillery (UFLA/Brazil) & UFLA CA803 & Distillery (UFLA/Brazil) \\
\hline UFLA CA771 & Distillery (UFLA/Brazil) & UFLA CA804 & Distillery (UFLA/Brazil) \\
\hline UFLA CA772 & Distillery (UFLA/Brazil) & UFLA CCA 022 & Distillery (UFLA/Brazil) \\
\hline UFLA CA773 & Distillery (UFLA/Brazil) & UFLA CCA 035 & Distillery (UFLA/Brazil) \\
\hline UFLA CA774 & Distillery (UFLA/Brazil) & UFLA CCA 083 & Distillery (UFLA/Brazil) \\
\hline UFLA CA775 & Distillery (UFLA/Brazil) & UFLA CCA 385 & Distillery (UFLA/Brazil) \\
\hline
\end{tabular}




\section{Screening for stressful conditions}

\section{Temperature, ethanol, sulfite and osmolarity tolerance}

The temperature tolerance test was performed according to Breisha (2010) at 30,37 and $42{ }^{\circ} \mathrm{C}$. Tolerance to ethanol concentrations was evaluated according to Breisha (2010) at 0, 6, 12 and 18\% ethanol. The sulfite tolerance test was carried out according to Valles et al. (2008) in $0.02 \%$ and $0.04 \%(\mathrm{w} / \mathrm{v})$ sodium metabisulfite. Osmolarity tolerance was observed after incubation of the strains for $72 \mathrm{~h}$ at $30{ }^{\circ} \mathrm{C}$ in YPD medium $\left(10 \mathrm{~g} \mathrm{~L}^{-1}\right.$ Yeast extract; $20 \mathrm{~g} \mathrm{~L}^{-1}$ Peptone; $20 \mathrm{~g} \mathrm{~L}^{-1}$ dextrose; $14 \mathrm{~g} \mathrm{~L}^{-1}$ agar) supplemented with $0,0.5,0.7$ and $1 \mathrm{~mol} \mathrm{~L}^{-1} \mathrm{NaCl}$ according to Rep et al. (2000) with modifications. Tolerance to $\mathrm{NaCl}$ concentrations was observed by measuring colony size.

\section{Flocculation evaluation by spectrophotometry}

Flocculation was determined according to Valles et al. (2008) with some modifications. The yeast strains were inoculated in $5 \mathrm{~mL}$ of YPD broth and incubated at $30{ }^{\circ} \mathrm{C}$ for $72 \mathrm{~h}$. After incubation, the cell cultures were centrifuged and the cells were resuspended in $5 \mathrm{~mL}$ of Helm's buffer ( $3 \mathrm{~m} \mathrm{~mol} \mathrm{~L}^{-1}$ calcium chloride, $50 \mathrm{~m} \mathrm{~mol} \mathrm{~L}^{-1}$ acetate-acetic buffer, $\mathrm{pH} 4.5$ ). The degree of flocculation of the different strains was determined in terms of the ratio between the optical density at $620 \mathrm{~nm}$ of the culture suspension and that obtained $10 \mathrm{~min}$ after the Helm's buffer was added $\left(\mathrm{OD}_{10} / \mathrm{OD}_{0} \times 100\right)$. The following flocculation scale was established: ratio $>90 \%$ (no flocculence); ratio between $70 \%$ and $90 \%$ (low flocculence); ratio between $30 \%$ and $70 \%$ (medium flocculence); and ratio $<30 \%$ (high flocculence).

\section{Screening of S. cerevisiae strains for ethanol and glycerol production}

Cells were grown in YPS $\left(10 \mathrm{~g} \mathrm{~L}^{-1}\right.$ Yeast extract; $20 \mathrm{~g}$ $\mathrm{L}^{-1}$ Peptone; $20 \mathrm{~g} \mathrm{~L}^{-1}$ Sucrose) at $30^{\circ} \mathrm{C}$. After $36 \mathrm{~h}$, cells corresponding to an optical density of 2.0 at $600 \mathrm{~nm}$ were used to inoculate $(5 \% \mathrm{v} / \mathrm{v})$ the ethanol production medium (40 $\mathrm{g} \mathrm{L}^{-1}$ sucrose; $5 \mathrm{~g} \mathrm{~L}^{-1}$ yeast extract; $20 \mathrm{~g} \mathrm{~L}^{-1}$ peptone; $0.5 \mathrm{~g} \mathrm{~L}^{-1} \mathrm{KH}_{2} \mathrm{PO}_{4} ; 0.5 \mathrm{~g} \mathrm{~L}^{-1}\left(\mathrm{NH}_{4}\right)_{2} \mathrm{SO}_{4} ; 0.5 \mathrm{~g} \mathrm{~L}^{-1}$ $\mathrm{MgSO}_{4} 7 \mathrm{H}_{2} \mathrm{O}$ ). The flasks were incubated at $30{ }^{\circ} \mathrm{C}$ for 5 days. The ethanol and glycerol concentrations were evaluated by high-performance liquid chromatography (HPLC), according to Duarte et al. (2009).

\section{Performance of $S$. cerevisiae strains during alcoholic fermentation}

\section{Fermentation assays}

The yeast isolates were grown in 250-mL flasks containing $100 \mathrm{~mL}$ of YPD medium for $24 \mathrm{~h}$ at $30{ }^{\circ} \mathrm{C}$ and $200 \mathrm{rpm}$. After measuring the absorbance at $600 \mathrm{~nm}$, the cell suspension volume was adjusted to obtain an inoculum corresponding to an optical density of 2.0 (approximately $1.0 \times 10^{8}$ cells $\mathrm{mL}^{-1}$ ) and were inoculated in $100 \mathrm{~mL}$ of sugar cane juice at $18^{\circ}$ Brix and incubated at $30^{\circ} \mathrm{C}$ without agitation. The experiment was conducted in duplicate. Samples were collected at intervals of $4 \mathrm{~h}$ to determine the concentrations of residual sugar, acetic acid, glycerol and ethanol produced.

\section{Chemical analysis}

Sugar contents (sucrose, glucose and fructose), organic acids (acetic acid and succinic acid), glycerol, methanol and ethanol were quantified by HPLC, according to Duarte et al. (2009).

\section{Calibration curves}

Yeast strains were grown in $250-\mathrm{mL}$ flasks containing $100 \mathrm{~mL}$ of YPD broth for $24 \mathrm{~h}$ at $30{ }^{\circ} \mathrm{C}$ and $200 \mathrm{rpm}$. After the 24-h incubation, the yeast cells were centrifuged $(6000 \mathrm{~g})$ for $5 \mathrm{~min}$ at $20{ }^{\circ} \mathrm{C}$ and washed twice with sterile peptone water. The biomass obtained was inoculated into $100 \mathrm{~mL}$ of sugar cane juice at $18{ }^{\circ}$ Brix and incubated at $30{ }^{\circ} \mathrm{C}$ for $36 \mathrm{~h}$ without agitation. After growth, the cells were recovered by centrifugation $(6000 \mathrm{~g})$ for $5 \mathrm{~min}$ at $20{ }^{\circ} \mathrm{C}$ and washed twice with sterile peptone water. The biomass was then resuspended in $30 \mathrm{~mL}$ of sterile peptone water $(0.1 \%)$, of which $15 \mathrm{~mL}$ was used to determine the dry weight at $105{ }^{\circ} \mathrm{C}$ after $24 \mathrm{~h}$. The remaining $15 \mathrm{~mL}$ was used for serial dilutions to determine the absorbance at $600 \mathrm{~nm}$. Calibration curves were obtained by plotting the absorbance values against the dry weight values. The calibration curves were used to determine the initial inoculum concentration and to monitor yeast growth during the fermentation process.

\section{Evaluation of the co-incubation of $S$. cerevisae UFLA FW221 and L. fermentum during alcoholic fermentation}

The fermentation was performed as previously described. The L. fermentum isolated from distillery and belonging to the culture collection of the Microbial Physiology Laboratory/Department of Biology/Federal University of Lavras (UFLA), Brazil was employed in this study. Flasks containing $100 \mathrm{~mL}$ of sugarcane juice at $18^{\circ} \mathrm{Brix}$ were inoculated separately with (1) L. fermentum $\left(10^{6} \mathrm{cfu}\right.$ $\left.\mathrm{mL}^{-1}\right)$, (2) S. cerevisiae UFLA FW221 $\left(10^{8} \mathrm{cfu} \mathrm{mL}^{-1}\right)$ and (3) with a mixed culture of L. fermentum and S. cerevisiae UFLA FW221 (10 $\mathrm{cfu} \mathrm{mL}^{-1}$ bacteria; $10^{8} \mathrm{cfu} \mathrm{mL}^{-1}$ yeast). Samples were microbiological analyzed by plating in YPD medium for yeast and Man Rogosa Sharpe (MRS, Merck, Darmstadt, Germany) medium for bacteria, and by HPLC (Duarte et al., 2009) for chemical contents.

\section{Batch scale fermentation}

Fermentation using the selected strain $S$. cerevisiae UFLA FW221 was carried out in 20-L stainless steel vats during five consecutive batches. The selected $S$. cerevisiae strain was grown in $1 \mathrm{~mL}$ YPD broth at $30{ }^{\circ} \mathrm{C}$ on an orbital 
shaker at $150 \mathrm{rpm}$ for $24 \mathrm{~h}$ and then transferred to tubes containing $9 \mathrm{~mL}$ of YPD broth. These tubes were incubated at $30{ }^{\circ} \mathrm{C}$ on an orbital shaker at $150 \mathrm{rpm}$ for $24 \mathrm{~h}$ and then transferred to $90 \mathrm{~mL}$ of YPD broth under the same conditions. Then, $100 \mathrm{~mL}$ of each of the grown cultures was transferred to $900 \mathrm{~mL}$ of YPD incubated under the same conditions and replicated to obtain a final population of $10^{8} \mathrm{cfu} \mathrm{mL} \mathrm{m}^{-1}$. Thus, a volum of $200 \mathrm{~mL}$ of cell suspension (inoculum) was added to stainless vats containing $20 \mathrm{~L}$ of sugar cane juice at $18{ }^{\circ}$ Brix. The fermentation was considered finished when the sugar concentration was zero ${ }^{\circ}$ Brix. In general, each fermentation cycle spent around 20 to $24 \mathrm{~h}$. Samples were collected at the beginning and the end of each fermentation batch. Analyses of sugars, ethanol and organic acids were performed by HPLC (Duarte et al., 2009).

Karyotyping profiles of the strains isolated during the batches were obtained by Pulsed Field Gel Electrophoresis (PFGE), according to Pereira et al. (2010). Analyses of viability were performed by fluorescence microscopy using a Live/Dead Yeast Viability kit (Molecular Probes) according to the manufacturer's instructions and methylene blue staining. Yeast cell trehalose was also estimated by HPLC, according to Ferreira et al. (1997).

\section{Evaluation of the fermentation performance}

To determine the fermentation performance, conversion factors were used for calculating the conversion of substrates $\left(\mathrm{g} \mathrm{g}^{-1}\right)$ into ethanol $\left(Y_{\mathrm{p} / \mathrm{s}}\right)$, biomass $\left(Y_{\mathrm{x} / \mathrm{s}}\right)$, glycerol $\left(Y_{\mathrm{g} / \mathrm{s}}\right)$, methanol $\left(Y_{\mathrm{m} / \mathrm{s}}\right)$, succinic acid $\left(Y_{\text {sucks }}\right)$ and acetic acid $\left(Y_{\mathrm{ac} / \mathrm{s}}\right)$, and also volumetric productivity $\left(\mathrm{g} \mathrm{L}^{-1} \mathrm{~h}^{-1}\right)$ of ethanol $\left(Q_{\mathrm{p}}\right)$, biomass productivity $\left(\mathrm{g} \mathrm{g}^{-1} \mathrm{~h}^{-1}\right)\left(P_{\mathrm{x}}\right)$, conversion efficiency $(\%)\left(E_{\mathrm{f}}\right)$ and percentage of conversion relative to the theoretical value (conversion (\%)) (Duarte et al., 2010).

The equations used in this work are presented below:

$$
Y_{\mathrm{p} / \mathrm{s}}=\left(\mathrm{P}_{f}-\mathrm{P}_{i}\right) /\left(\mathrm{S}_{i}-\mathrm{S}_{f}\right) ; Y_{\mathrm{x} / \mathrm{s}}=\left(\mathrm{X}_{f}-\mathrm{X}_{i}\right) /\left(\mathrm{S}_{i}-\mathrm{S}_{f}\right) ; Y_{\mathrm{g} / \mathrm{s}}=
$$
$\left(\mathrm{g}_{f}-\mathrm{g}_{i}\right) /\left(\mathrm{S}_{i}-\mathrm{S}_{f}\right)$

$Y_{\mathrm{m} / \mathrm{s}}=\left(\mathrm{M}_{f}-\mathrm{M}_{i}\right) /\left(\mathrm{S}_{i}-\mathrm{S}_{f}\right) ; Y_{\mathrm{suc} / \mathrm{s}}=\left(\mathrm{Suc}_{f}-\mathrm{Suc}_{i}\right) /\left(\mathrm{S}_{i}-\mathrm{S}_{f}\right) ;$ $Y_{\mathrm{ac} / \mathrm{s}}=\left(\mathrm{Ac}_{f}-\mathrm{Ac}_{i}\right) /\left(\mathrm{S}_{i}-\mathrm{S}_{f}\right) ; Q_{\mathrm{p}}=\left(\mathrm{P}_{f}-\mathrm{P}_{i}\right) / \mathrm{t}_{f} ; P_{\mathrm{x}}=\left(\mathrm{X}_{f}-\mathrm{X}_{i}\right) / \mathrm{t}_{f} ;$ $E f=\left(Y_{\mathrm{p} / \mathrm{s}} / 0.51\right) \times 100 ;$ conversion $(\%)=\left(Y_{\mathrm{p} / \mathrm{s}} / 0.51\right) / 100$;

where $\mathrm{P}_{i}$ is the initial concentration of ethanol, $\mathrm{P}_{f}$ is the ethanol concentration at the end of fermentation, $\mathrm{S}_{i}$ is the initial substrate concentration, $\mathrm{S}_{f}$ is the substrate concentration at the end of fermentation, $\mathrm{X}_{i}$ is the initial biomass concentration, $\mathrm{X}_{f}$ is the biomass concentration at the end of fermentation, $\mathrm{g}_{i}$ is the initial glycerol concentration, $\mathrm{g}_{f}$ is the glycerol concentration at the end of fermentation, $\mathrm{Ac}_{i}$ is the initial acetic acid concentration, $\mathrm{Ac}_{f}$ is the concentration of acetic acid at the end of fermentation, $\mathrm{M}_{i}$ is the initial methanol concentration, $\mathrm{M}_{f}$ is the concentration at the end of fermentation, $\mathrm{Suc}_{f}$ is the succinic acid concentration at the end of fermentation, $\mathrm{Suc}_{i}$ is the initial succinic acid concentration and $\mathrm{t}_{f}$ is the total time of fermentation.

\section{Statistical analysis}

Cluster analysis was performed by using the software Statistica for Windows, version 6.0 (Statsoft Inc., Tulsa, OK, USA) The binary matrix was constructed with the results of growth (+) or no growth (-) for each level of treatment according to methods described above, regarding ethanol and glycerol screening the production of ethanol higher than $10 \mathrm{~g} \mathrm{~L}^{-1}$ and glycerol less than $3 \mathrm{~g} \mathrm{~L}^{-1}$ were considered positive $(+)$ in the binary matrix. Principal component analyses (PCA) were performed using the XLSTAT 7.5.2 software (Addinsoft's, New York, NY, USA). $\mathrm{CO}_{2}$ production $(d \mathrm{CO} 2 / d \mathrm{t})$ was calculated using the Origin Pro 8.0 software (OriginLab, Northampton, MA, USA). Analyses of the variance by Scott-Knott test were performed with SISVAR 5.1 software (Ferreira, 2008).

\section{Results}

\section{Screening of $S$. cerevisiae for stress tolerance and ethanol production}

Figure 1 shows the grouping of yeasts according to their behavior under different growth conditions, such as different temperatures $\left(30,37\right.$ and $\left.42^{\circ} \mathrm{C}\right), \mathrm{NaCl}$ concentrations $\left(0.5,0.7\right.$ and $\left.1 \mathrm{~mol} \mathrm{~L}^{-1}\right)$, sulfite concentrations $(0.02$

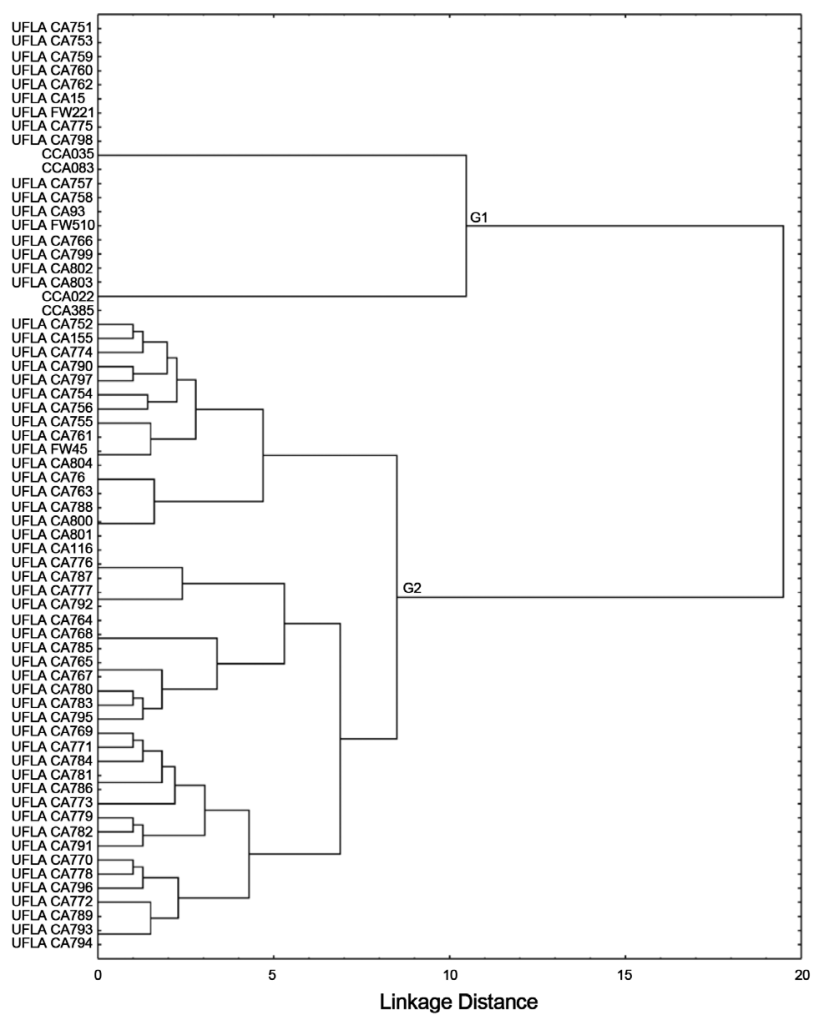

Figure 1 - Dendrogram obtained by Ward's hierarchical clustering method performed for different growth conditions (temperature, osmolarity, sulfite and ethanol tolerance and flocculation capacity). G1 = most resistant strains (Growth at $42{ }^{\circ} \mathrm{C}$, in $1 \mathrm{M} \mathrm{NaCl}, 0.04 \%$ (w/v) sulfite and tolerated $12 \%$ ethanol. They were not flocculent) and G2 = most sensitive strains. 
and $0.04 \%, \mathrm{w} / \mathrm{v})$, ethanol concentrations $(0,6,12$ and $18 \%)$ and flocculation capacity. The 66 yeast strains were classified into two large groups (G1 and G2). The G1 group contains the yeast strains that were able to support the most stressful conditions. The $S$. cerevisiae strains included in this group were able to grow at $42{ }^{\circ} \mathrm{C}$, in $1 \mathrm{M} \mathrm{NaCl}, 0.04 \%$ $(\mathrm{w} / \mathrm{v})$ sulfite and tolerated $12 \%$ ethanol. There were no flocculant strains among those in G1. These results demonstrate that these strains were well adapted to adverse conditions.

Ethanol production was also evaluated during the yeast selection process. Strains of Saccharomyces that were resistant for the most stressful conditions and produced more than $10 \mathrm{~g} \mathrm{~L}^{-1}$ of ethanol were selected to study the fermentation behavior in sugar cane juice.

\section{Fermentative behavior of $S$. cerevisiae strains in sugar cane juice}

A total of 18 non-flocculent strains were selected to produce ethanol from sugar cane juice fermentation. These strains included fruit wine and distilleries isolates. $S$. cerevisiae PE-2, commercially used in Brazil for ethanol production, was also used as a reference to compare with the indigenous strains selected.

The results obtained from the kinetic parameters were subjected to PCA. Three initial principal components (PC) accounted for $73.68 \%$ of the total initial variance. Figure 2 shows the plot of the PCA for the first (PC1) and the second (PC2) principal components, which explains 56.03 and $17.65 \%$ of the total variance, respectively. The values for $Y_{\mathrm{p} / \mathrm{s}}$ ranged from $0.21 \mathrm{~g} \mathrm{~g}^{-1}$ to $0.46 \mathrm{~g} \mathrm{~g}^{-1}$. The strains UFLA FW221, CCA083, UFLA CA798, UFLA CA759, UFLA CA93, UFLA FW510 and UFLA CA762 showed higher $Y_{\mathrm{p} / \mathrm{s}}, 0.46,0.44,0.43,0.43,0.40,0.39$ and $0.39 \mathrm{~g} \mathrm{~g}^{-1}$, respectively. The industrial strain PE-2 isolated from a distillery and studied by Basso et al. (2008) for ethanol fuel production showed a value of $Y_{\mathrm{p} / \mathrm{s}}$ of $0.38 \mathrm{~g} \mathrm{~g}^{-1}$. This value was lower than the values obtained by indigenous strains evaluated in this work.

The conversion factor of $Y_{\mathrm{g} / \mathrm{s}}$ ranged from $0.04 \mathrm{~g} \mathrm{~g}^{-1}$ to $0.09 \mathrm{~g} \mathrm{~g}^{-1}$. Strains UFLA CA759, UFLA FW211, UFLA CA798 and CCA083 showed the lowest values of $Y_{\mathrm{g} / \mathrm{s}}$ corresponding to $0.05 \mathrm{~g} \mathrm{~g}^{-1}$ for strains UFLA CA759 and UFLA CCA083 and $0.06 \mathrm{~g} \mathrm{~g}^{-1}$ for the other two. Acetic acid production was not detected for any of the 18 selected yeasts. The methanol conversion $\left(Y_{\mathrm{m} / \mathrm{s}}\right)$ was $0.01 \mathrm{~g} \mathrm{~g}^{-1}$ for all strains except for UFLA CA753, whose value was $0.02 \mathrm{~g} \mathrm{~g}^{-1}$.

The strains UFLA CA759, UFLA CA798, UFLA FW211 and CCA083 were then tested in fermentation with sugar cane juice, and calibration curves were performed to determine the initial inoculum concentration and to monitor yeast growth during the fermentation process. Figure 3 shows the PCA analysis based on the results obtained during fermentation for the four selected yeast strains. Three

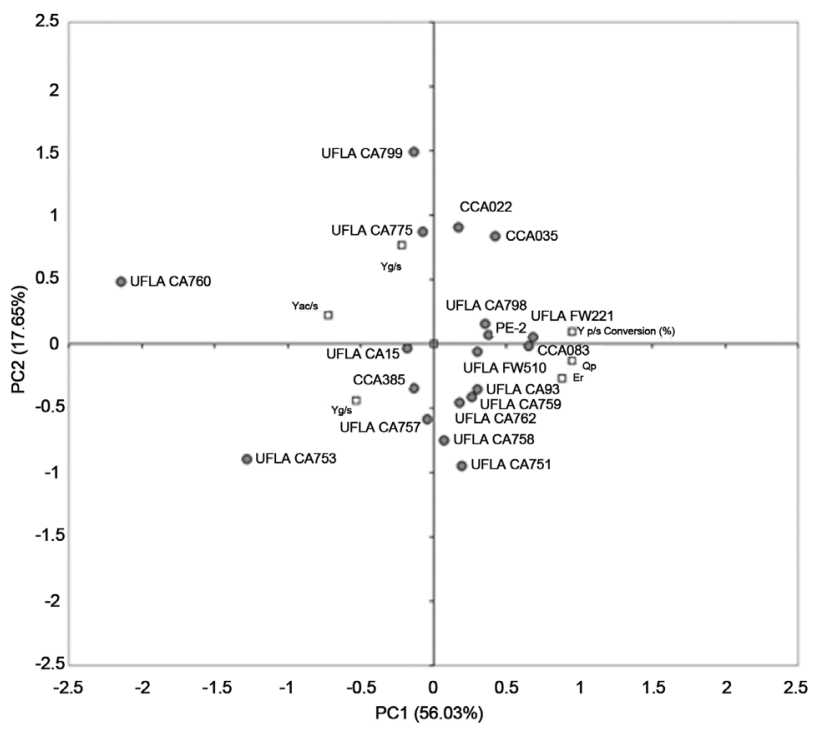

Figure 2 - Principal component analysis (PCA) of the kinetic parameters of 19 S. cerevisiae strains in sugar cane juice.

initial principal components (PC) accounted for $75.62 \%$ of the total initial variance; the first (PC1) and the second (PC2) principal components explained 46.97 and $28.65 \%$ of the total variance, respectively.

Table 2 shows the values of the fermentative parameters, the data did not differ significantly $(\mathrm{p}<0.05)$ by Scott-Knott test, however the UFLA FW211 strain showed the highest value of $Y_{\mathrm{p} / \mathrm{s}}\left(0.50 \mathrm{~g} \mathrm{~g}^{-1}\right)$ among all evaluated strains. The parameters $Y_{\mathrm{ac} / \mathrm{s}}, Y_{\mathrm{g} / \mathrm{s}}$ and $Y_{\mathrm{suc} / \mathrm{s}}$ were similar among the UFLA CA759, UFLA CA798, UFLA FW211 and CCA083 strains. There was no production of acetic acid; the $Y_{\mathrm{g} / \mathrm{s}}$ value was $0.05 \mathrm{~g} \mathrm{~g}^{-1}$ for the UFLA CA759 strain and $0.06 \mathrm{~g} \mathrm{~g}^{-1}$ for the other three strains, and $Y_{\text {suc/s }}$ was $0.01 \mathrm{~g} \mathrm{~g}^{-1}$ for all four strains. The maximum value of $Y_{\mathrm{x} / \mathrm{s}}$ was $0.06 \mathrm{~g} \mathrm{~g}^{-1}$ for UFLA CA759, and the minimum was

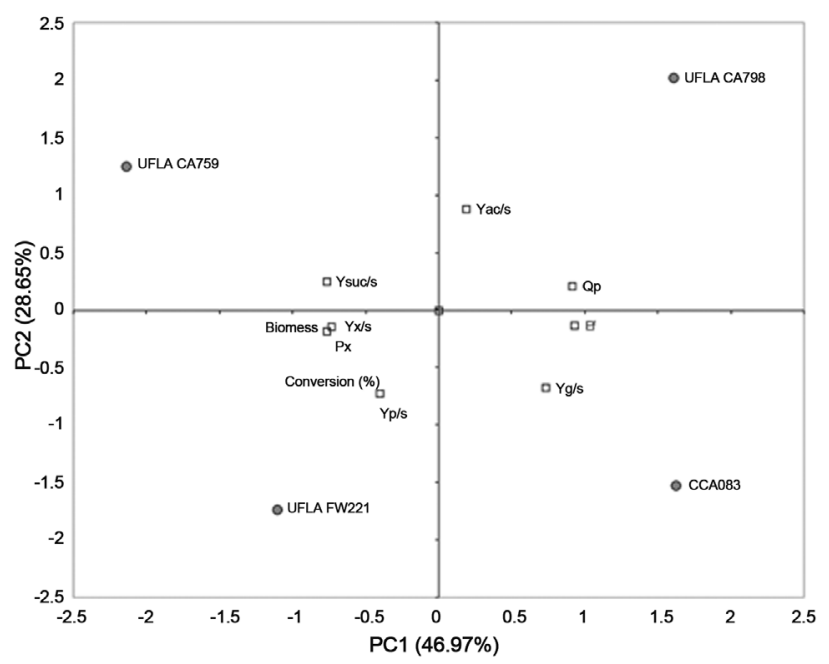

Figure 3 - Principal component analysis (PCA) of the kinetic parameters of four selected $S$. cerevisiae strains in sugar cane juice. 
Table 2 - Fermentative parameters calculated from four selected Saccharomyces cerevisiae strains.

\begin{tabular}{lccccccc}
\hline Yeast strain & \multicolumn{7}{c}{ Fermentative parameters } \\
\cline { 2 - 7 } & Yp/s & Yg/s & Qp & Yx/s & Ysuc/s & $\%$ & Px \\
\hline UFLA CA759 & $0.47 \pm 0.01^{\mathrm{a}}$ & $0.05 \pm 0.001^{\mathrm{a}}$ & $2.81 \pm 0.03^{\mathrm{a}}$ & $0.06 \pm 0.004^{\mathrm{a}}$ & $0.01 \pm 0.000^{\mathrm{a}}$ & $91 \pm 2.0^{\mathrm{a}}$ & $0.39 \pm 0.03^{\mathrm{a}}$ \\
UFLA CA798 & $0.46 \pm 0.02^{\mathrm{a}}$ & $0.06 \pm 0.003^{\mathrm{a}}$ & $2.85 \pm 0.07^{\mathrm{a}}$ & $0.01 \pm 0.000^{\mathrm{a}}$ & $0.01 \pm 0.000^{\mathrm{a}}$ & $90 \pm 5.7^{\mathrm{a}}$ & $0.04 \pm 0.00^{\mathrm{a}}$ \\
UFLA FW221 & $0.50 \pm 0.01^{\mathrm{a}}$ & $0.06 \pm 0.002^{\mathrm{a}}$ & $2.80 \pm 0.04^{\mathrm{a}}$ & $0.04 \pm 0.002^{\mathrm{a}}$ & $0.01 \pm 0.000^{\mathrm{a}}$ & $99 \pm 2.7^{\mathrm{a}}$ & $0.19 \pm 0.00^{\mathrm{a}}$ \\
CCA 083 & $0.47 \pm 0.01^{\mathrm{a}}$ & $0.06 \pm 0.00^{\mathrm{a}}$ & $2.85 \pm 0.01^{\mathrm{a}}$ & $0.04 \pm 0.002^{\mathrm{a}}$ & $0.01 \pm 0.000^{\mathrm{a}}$ & $92 \pm 1.3^{\mathrm{a}}$ & $0.23 \pm 0.01^{\mathrm{a}}$ \\
\hline
\end{tabular}

Presented values are means of duplicate determinations; \pm indicates standard deviations from the mean. Mean values $( \pm$ standard deviation) within the same column followed by different superscript letters differ significantly $(\mathrm{p}<0.05)$ by Scott-Knott test.

$0.01 \mathrm{~g} \mathrm{~g}^{-1}$ for the UFLA CA798 strain. The $Y_{\mathrm{x} / \mathrm{s}}$ value obtained from UFLA FW211 was $0.04 \mathrm{~g} \mathrm{~g}^{-1}$.

These results showed that the four $S$. cerevisiae strains UFLA CA759, UFLA CA798, UFLA FW211 and CCA083 were able to adapt and to ferment the sugar cane juice quickly. However, since the strain UFLA FW221 presented the higher value of $\mathrm{Y}_{\mathrm{p} / \mathrm{s}}$ this strain was selected for further studies.

\section{Behavior of S. cerevisae UFLA FW221 in co-culture with L. fermentum}

Fermentation monitoring was based on the production rate of $\mathrm{CO}_{2}\left(d \mathrm{CO}_{2} / d t\right)$, carbohydrate consumption and ethanol production (Figure 4). The rates of $\mathrm{CO}_{2}$ production ranged from approximately 0.3 to $0.35 \mathrm{~g} \mathrm{~L}^{-1} \mathrm{~h}^{-1}$, where the maximum $\mathrm{CO}_{2}$ production rate was obtained approximately $12 \mathrm{~h}$ after the beginning of the fermentative process. The strain PE-2 was employed as a reference, because it is successfully employed in Brazilian industrial fermentations. According to $\mathrm{CO}_{2}$ rates, both strains showed similar performance when it was inoculated single or in co-culture with $L$. fermentum. All yeast strains showed a similar behavior for carbohydrate consumption, and ethanol production (Figure 4).

\section{Batch scale fermentation}

Fermentation was carried out in five consecutive batches using the selected strain UFLA FW221. Pulsed Field Gel Electrophoresis analysis were performed to observe if the yeast is genetically stable during the batches (Figure 5), fluorescence microscopy was performed to assess cell viability (Figure 6), and analyses of ethanol, glycerol, organic acids, trehalose (Table 3 ) and biomass (Figure 7) were also carried out to observe the fermentative characteristics of the yeasts during the batches. All colonies isolated during the batches had the same chromosomal profile, shown in Figure 5 and were identical to the corresponding inoculated yeast UFLA FW221. Figure 6 shows the fluorescent image of the yeast at the end of the fifth batch of fermentation. It was observed that the inoculated yeast remained viable until the last of the five batches even at high alcohol concentrations (approximately $77.4 \mathrm{~g} \mathrm{~L}^{-1}$ ).
Table 2 shows that high volumes of ethanol were produced during the batches, reaching levels up to $77 \mathrm{~g} \mathrm{~L}^{-1}$ (approximately $10 \% \mathrm{v} / \mathrm{v}$ ) of ethanol. The values of glycerol were approximately $5 \mathrm{~g} \mathrm{~L}^{-1}$ and succinic acid $1 \mathrm{~g} \mathrm{~L}^{-1}$. Acetic acid production was not observed.
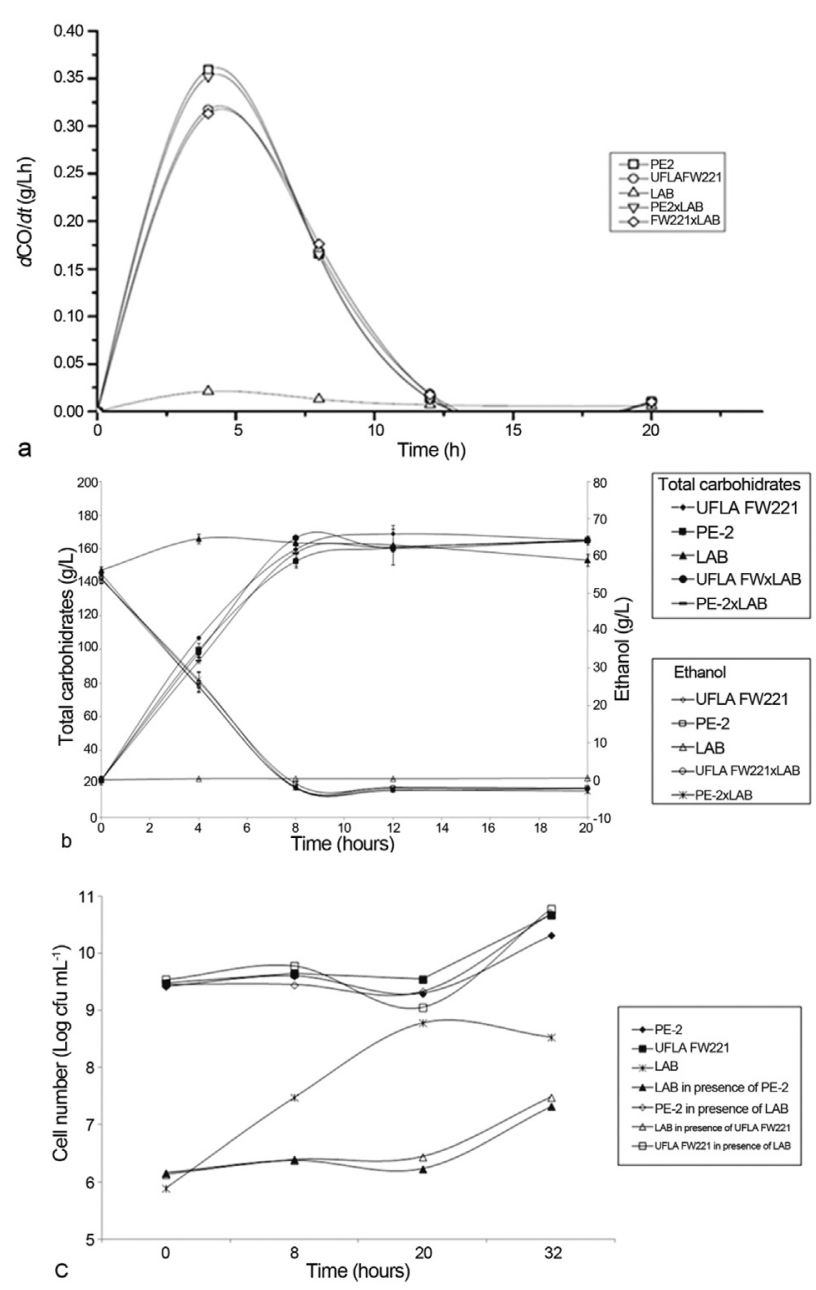

Figure 4 - Results obtained in the fermentation employing $S$. cerevisae UFLA FW221 in co-culture with $L$. fermentum . a. Rates of $\mathrm{CO}_{2}\left(d \mathrm{CO}_{2} / d t\right)$ production; b. Carbohydrates and ethanol yields; c. Growth of $S$. cerevisiae UFLA FW221 and L. fermentum strains evaluated by plating in YPD and MRS medium, respectively, in pure and co-culture during sugar cane juice fermentation. 


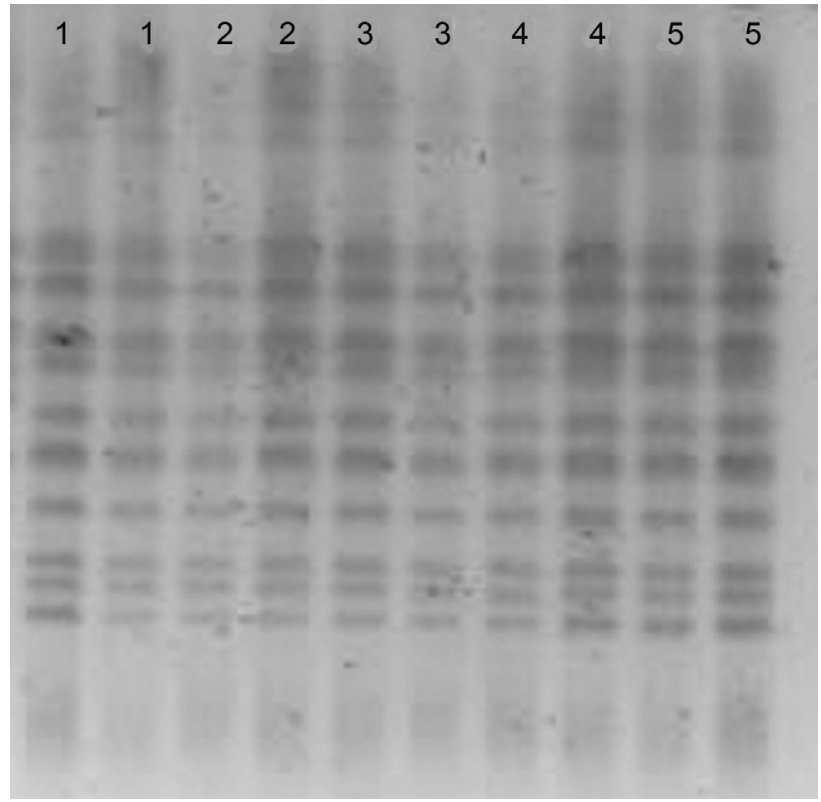

Figure 5 - Pulsed Field Gel Electrophoresis (PFGE) of strains isolated in the five batches. Numbers represents the batches.

The $S$. cerevisiae strain UFLA FW221 was able to accumulate intracellular trehalose (about $32 \mu \mathrm{mol}$ trehalose per $g$ of wet weight) at the end of five batches (Table 2).

\section{Discussion}

In general, it is known that industrial process to produce ethanol is harsh for yeast. Therefore, suitable yeast is an important factor to obtain success in productivity. Stressful conditions affect yeast cell metabolism, leading to loss of cell viability and fermentation ability. Resistance to stress conditions is strain-dependent. The yeasts into G1 group were able to grow in higher temperature $\left(42^{\circ} \mathrm{C}\right)$ and ethanol concentration (12\%) and also they were osmo- and sulphite- ( $1 \mathrm{M} \mathrm{NaCl}$ and $0.04 \%$, respectively) tolerant. Thus, they displayed characteristics to tolerate these unfa-

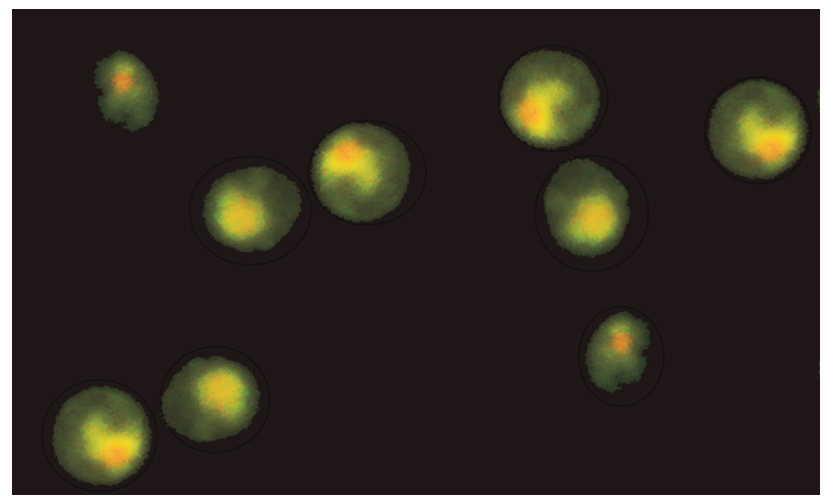

Figure 6 - Viable $S$. cerevisiae cells stained with the Live/Death Yeast Viability kit and viewed by fluorescent microscopy after five batches.

vorable conditions imposed by industrial process. The temperature during the fermentation process in Brazil can reach $40{ }^{\circ} \mathrm{C}$ and the maximum ethanol concentration, which increases gradually, reaches approximately 8 to $11 \%$ $(\mathrm{v} / \mathrm{v})$ at the end of the process (Basso et al., 2008). Hence, the G1 strains are probably able to survive until the end of the high ethanol processes. The ability to adapt to changes in the osmolarity of the surrounding medium is fundamental to life, and the accumulation of compatible solutes to decrease intracellular water potential is an adaptation strategy employed by all cell types (Rep et al., 2000). Thus, yeast osmotolerance may be an important factor in ethanol production. Since sulfite and sulfite-generating compounds have long been used as antimicrobial agents in alcoholic fermentation (Walker, 1998), sulfite tolerance in yeast is another desired trait for bioethanol production from sugar cane juice.

Yeast flocculation capacity is considered an important characteristic for some fermentative industrial processes (Campos et al., 2010; Schwan et al., 2001; Stewart and Russell, 1981). However, in the bioethanol industry, flocculent yeast cells can obstruct the pipes and reduce cell-substrate contact, which increases the fermentation

Table 3 - Concentrations $\left(\mathrm{g} \mathrm{L}^{-1}\right)$ of total sugar, ethanol, glycerol, organic acids and intracellular trehalose contents detected in sugar cane juice fermentation after five batches with the UFLA FW221 strain.

\begin{tabular}{|c|c|c|c|c|c|c|}
\hline & \multirow{2}{*}{$\begin{array}{l}\text { Sugar cane } \\
\text { juice }\end{array}$} & \multicolumn{5}{|c|}{ End of batches } \\
\hline & & 1 & 2 & 3 & 4 & 5 \\
\hline Residual Total sugar $\left(\mathrm{g} \mathrm{L}^{-1}\right)$ & 169.27 & $3.51 \pm 0.62$ & $2.83 \pm 0.28$ & $8.69 \pm 1.56$ & $13.66 \pm 3.20$ & $1.91 \pm 1.03$ \\
\hline Ethanol $\left(\mathrm{g} \mathrm{L}^{-1}\right)$ & ND & $67.00 \pm 8.68$ & $76.50 \pm 1.81$ & $77.38 \pm 5.43$ & $71.36 \pm 6.36$ & $73.41 \pm 3.21$ \\
\hline Glycerol ( $\left.\mathrm{g} \mathrm{L}^{-1}\right)$ & ND & $5.57 \pm 0.40$ & $5.84 \pm 0.15$ & $5.67 \pm 0.57$ & $5.16 \pm 0.44$ & $5.16 \pm 0.20$ \\
\hline Succinic acid $\left(\mathrm{g} \mathrm{L}^{-1}\right)$ & 0.40 & $1.29 \pm 0.01$ & $1.33 \pm 0.02$ & $1.20 \pm 0.14$ & $1.11 \pm 0.14$ & $0.97 \pm 0.07$ \\
\hline Citric acid $\left(\mathrm{g} \mathrm{L}^{-1}\right)$ & 0.15 & $0.79 \pm 0.02$ & $0.81 \pm 0.10$ & $0.70 \pm 0.11$ & $0.68 \pm 0.07$ & $0.58 \pm 0.01$ \\
\hline Acetic acid $\left(\mathrm{g} \mathrm{L}^{-1}\right)$ & ND & ND & ND & ND & ND & ND \\
\hline Trehalose ( $\mu \mathrm{mol}$ glucose $\mathrm{g}$ wet weight $\left.{ }^{-1}\right)$ & - & $25.39 \pm 3.01$ & $20.34 \pm 4.90$ & $20.42 \pm 2.28$ & $25.55 \pm 4.45$ & $31.99 \pm 0.87$ \\
\hline
\end{tabular}

$\mathrm{ND}=$ not detected 


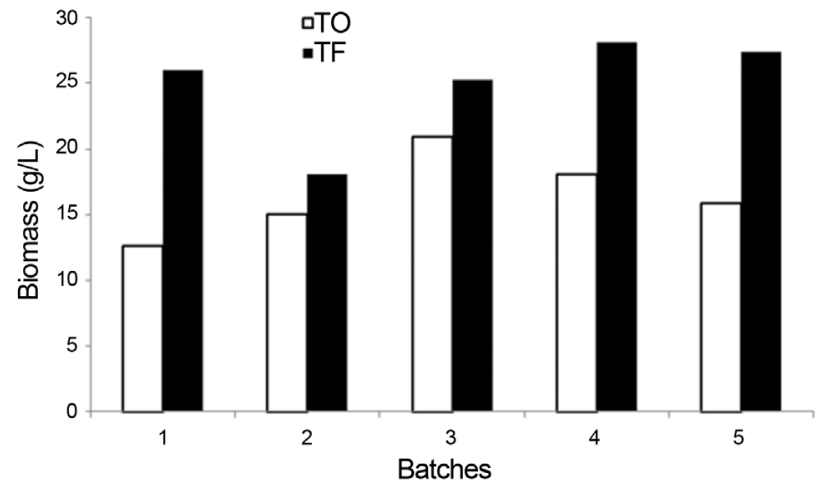

Figure 7 - Biomass production by UFLA FW221 during five batches $(20 \mathrm{~L})$ in sugar cane juice fermentation. $\mathrm{T} 0=$ initial time of batch, $\mathrm{TF}=\mathrm{fi}$ nal time of batch.

time and the amount of residual sugar at the end of the fermentative process (Basso et al., 2008).

The strains into G1 group which produced more than $10 \mathrm{~g} \mathrm{~L}^{-1}$ of ethanol were tested in sugar cane fermentations. The Figure 2 present that all yeast strains grouped on the positive axis of $\mathrm{PC} 1$ displayed greater correlations among the $Y_{\mathrm{p} / \mathrm{s}}$, conversion (\%), $E_{\mathrm{f}}$ and $Q_{\mathrm{p}}$ parameters (Figure 2), which indicate that these yeasts are able to convert sugar cane juice into ethanol. The strains UFLA CA798, UFLA FW221, CCA083, UFLA FW510, UFLA CA93, UFLA CA762 and UFLA CA759 were closely related to the $Y_{\mathrm{p} / \mathrm{s}}$, $Q_{\mathrm{p}}$ and $E_{\mathrm{f}}$ parameters (Figure 2). The increase of these parametric values is related to the high yield of ethanol production (Andrietta et al., 2008).

The parameters related to the conversion of a substrate into secondary products, such as $Y_{\mathrm{g} / \mathrm{s}}, Y_{\mathrm{ac} / \mathrm{s}}$ and $Y_{\mathrm{m} / \mathrm{s}}$, are in the negative axis of PC1 and were low for all 18 selected strains.

It is known that glycerol formation is coupled to yeast growth and is also formed in response to stressful conditions (Walker, 1998). Glycerol is formed by yeasts at the beginning of fermentation. This period corresponds to the start of glyceropyruvic fermentation, which is the only way that yeasts can ensure the reoxidation of the $\mathrm{NADH}^{+} / \mathrm{H}^{+}$ coenzyme by reducing dihydroxyacetone to glycerol (Ribéreau-Gayon et al., 2006). Low levels of glycerol synthesis can be associated with an active metabolism for ethanol formation and implies better yeast fermentation performance.

Because the strains UFLA CA798, UFLA FW221, CCA083, UFLA FW510, UFLA CA93, UFLA CA762 and UFLA CA759 showed the best results in the last experimental step (higher $Y_{p / s}$ and lower $Y_{g / s}$ values), they were cultured in starvation medium to observe asci or pseudohyphae formation. The strains UFLA FW510, UFLA CA93 and UFLA CA762 showed pseudohyphae formation (data not shown), which is an undesirable characteristic in the ethanol industry. Cells exhibiting hyphae or filamentous morphologies also differ in their expression and accumula- tion of undesirable cell constituents and in their ability to be disrupted or fractionated (Gibbs et al., 2000).

The strains UFLA CA759, UFLA CA798, UFLA FW211 and CCA083 were selected for a second fermentation. Even though all four strains did not differ significantly $(p<0.05)$ by Scott-Knott test and all of them are able to convert sugar in ethanol in a great ratio, the strain FW221 exhibited the higher rate of conversion of substrate into product ( $99 \%$ of the theoretical value) and a lower conversion of substrate into secondary products. This strain showed a value of $0.50 \mathrm{~g} \mathrm{~g}^{-1}$ to $Y_{\mathrm{p} / \mathrm{s}}$. Ortiz-Muñiz et al. (2010) investigated the kinetics of ethanol fermentation using $S$. cerevisiae ITV-01 strain isolate from molasses in different conditions to determine the optimum fermentation conditions. They found in the optimal conditions that this strain obtained ethanol yield of $0.41 \mathrm{~g} \mathrm{~g}^{-1}$.

The parameters which represent conversion of carbohydrates into secondary products were low for all strains studied. The conversion factor for converting substrate into biomass $\left(Y_{\mathrm{x} / \mathrm{s}}\right)$ represents the growth capacity of a strain in the fermentation medium. The strain UFLA FW221 presented a value of 0.04 . It means that this strain was capable to use carbohydrates to convert part in ethanol and part in biomass and there were a good balance between these parameters. Marini et al. (2009) studied indigenous $S$. cerevisiae to produce cachaça from sugar cane and they found values of $Y_{\mathrm{x} / \mathrm{s}}$ greater than $0.09 \mathrm{~g} \mathrm{~g}^{-1}$ and $Y_{\mathrm{p} / \mathrm{s}}$ ranging from 0.25 to $0.40 \mathrm{~g} \mathrm{~g}^{-1}$. These values indicates that the strains to produce ethanol convert less carbohydrates in biomass and more in ethanol than cachaça strains. These results showed that the fruit fermentation isolate UFLA FW211 presented a high capacity for growth in sugar cane juice and produced a high volume of ethanol. Nowadays, suitable yeasts have been selected from distilleries process because they are resistant to stress conditions impose by industrial fermentation process (Basso et al., 2008). However, this work has showed the importance of studying microbial diversity from different habitats. This study presented an isolate from fruit fermentation with excellent fermentative characteristics in sugar cane juice.

In fermentation assay with mixed culture of $L$. fermentum and $S$. cerevisiae strains UFLA FW221 and PE-2, L. fermentum did not affect the fermentation performance of the yeasts (Figure 4). It was observed that in pure and co-cultures the carbohydrate consumption and ethanol production were similar (Figure 4b). According to $\mathrm{CO}_{2}$ measurements (Figure 4a), the sugar cane fermentation was not affected negatively by L. fermentum presence for both yeasts PE-2 and UFLA FW221. It is known that Lactobacillus species can contaminate ethanol plants and cause losses in productivity, since they may compete for nutrients (Wheals et al., 1999). Thus, the studied yeast strains which presented the same fermentative behavior in pure or co-culture with Lactobacillus is desirable, considering the initial population of $10^{8} \mathrm{CFU} \mathrm{mL}^{-1}$ and $10^{6} \mathrm{cfu} \mathrm{mL}^{-1}$ 
for yeast and bacteria, respectively. Besides this, it could avoid the over-use of antibiotics products to control the bacteria growth. Since, Yokoya and Oliva-Neto, (2001) showed that some biocides used in industrial fuel alcoholic fermentation in Brazil could affect yeast activity.

The growth of $S$. cerevisiae strains were not affected by the L. fermentum presence. However, the bacterial growth decline in the yeast presence (Figure 4c). In the literature, we can find some reports of yeast and bacterial interaction (Meignen et al., 2001). Nobre et al. (2007) reported that the lactic acid bacteria $(\mathrm{LAB})$ L. fermentum reduced the viability of $S$. cerevisiae. In the alcoholic fermentation of corn mash, when the mash was inoculated with the $S$. cerevisiae and $L$. fermentum at the same time, bacterial growth still occurred but was reduced by $94 \%$. The reduction in bacterial growth may be due to alcohol produced by the yeast which can exert inhibitory effects on the multiplication of lactobacilli (Thomas et al., 2001). The results observed in batch fermentations showed that the UFLA FW221 strain remained genetically stable in the five batches and presented high viability. These data are important for the selection of industrial strains because yeasts are recycled during long fermentation periods.

The strain UFLA FW221 was able to accumulate a great amount of trehalose approximately $32 \mu \mathrm{mol}$ trehalose per $g$ of wet weight. The mechanism by which the yeast protects against the stress imposed by the industrial process includes trehalose accumulation, the synthesis of molecular chaperones and the synthesis of antioxidative enzymes. Trehalose has been used as a good indicator of the ability of yeasts to withstand stressful conditions (Tanghe et al., 2006). Furthermore, trehalose metabolism has been suggested to be an important physiological criterion for yeast selection in biotechnological processes.

This study screened 66 indigenous $S$. cerevisiae strains and selected strains as potential candidates for use in industrial bioethanol processes. The behaviours of the four selected strains UFLA CA759, UFLA CA798, UFLA FW211 and CCA083 were studied in sugar cane juice. The UFLA FW221 strain isolated from fruit fermentation showed a higher $Y_{\mathrm{p} / \mathrm{s}}$ value $\left(0.50 \mathrm{~g} \mathrm{~g}^{-1}\right)$, corresponding to $99 \%$ of the theoretical value. This strain was subject to batch scale fermentation. It was observed that UFLA FW221 was suitable for ethanol production, producing approximately $10 \%(\mathrm{w} / \mathrm{v})$ ethanol from sugar cane juice in $24 \mathrm{~h}$. These results showed that despite being isolated from fruit fermentation, the UFLA FW221 strain demonstrated an excellent fermentative performance in sugar cane juice, showing the importance of studying microbial biodiversity for applications in biotechnology.

\section{Acknowledgments}

The Brazilian agencies Conselho Nacional de Desenvolvimento Científico e Tecnológico do Brasil (CNPQ),
Fundação de Amparo a Pesquisa do Estado de Minas Gerais (FAPEMIG) and CAPES (Coordenação de Aperfeiçoamento de Pessoal de Nível Superior) are acknowledged for financial support and scholarships.

\section{References}

Aguilera J, Randez-Gil F, Prieto JA (2007) Cold response in Saccharomyces cerevisiae: new functions for old mechanisms. FEMS Microbiol Rev 31:327-341.

Andrietta SR, Steckelber C, Andrietta MGS (2008) Study of flocculent yeast performance in tower reactors for bioethanol production in a continuous fermentation process with no cell recycling. Bioresource Technol 99:3002-3008.

Antoni D, Zeverlov VV, Schwarz WH (2007) Biofuels from microbes. Appl Microbiol Biotechnol 77:23 -35.

Attfield PV (1997) Stress tolerance: the key to effective strains of industrial baker's yeast. Nat Biotechnol 15:1351-1357.

Babiker MA, Abdel-Banat, Hoshida H, Ano A, Nonklang S, Akada R (2010) High-temperature fermentation: how can processes for ethanol production at high temperatures become superior to the traditional process using mesophilic yeast? Appl Microbiol Biot 85:861-867.

Basso LC, Amorim HV, Oliveira AJ, Lopes ML (2008) Yeast selection for fuel ethanol production in Brazil. FEMS Yeast Res 8:1155-1163.

Breisha GZ (2010) Production of 16\% ethanol from 35\% sucrose. Biomass Bioenerg 34:1243-1249.

Campos CR, Silva CF, Dias DR, Basso LC, Amorim H, Schwan RF (2010) Features of Saccharomyces cerevisiae as a culture starter for the production of the distilled sugar cane beverage, cachaça in Brazil. J Appl Microbiol 108:1871-1879.

Cardona CA, Sánchez OJ (2007) Fuel ethanol production: process design trends and integration opportunities. Bioresource Technol 98:2415-2457.

Duarte WF, Dias DR, Pereira GVM, Gervásio IM, Schwan RF (2009) Indigenous and inoculated yeast fermentation of gabiroba (Campomanesia pubescens) pulp for fruit wine production. J Ind Microbiol Biot 36:557-569.

Duarte WF, Dragone G, Dias DR, Oliveira JM, Teixeira JA, Almeida e Silva JB Schwan RF (2010) Fermentative behaviour of Saccharomyces strains during microvinification of raspberry juice (Rubus idaeus L.). Int J Food Microbiol 143:173-182.

Ferreira DF (2008) SISVAR: um programa para análise e ensino de estatística. Revista Symposium 6:36-41.

Ferreira JC, Paschodin VMF, Panek AD, Trugo LC (1997) Comparison of three different methods for trehalose determination in yeast extracts. Food Chem 2:251-254.

Fleet GH (2008) Wine yeasts for the future. FEMS Yeast Res 8:979-995.

Gibbs PA, Seviour RJ, Schmid F (2000) Growth of filamentous fungi in submerged cultureproblems and possible solutions. Crit Rev Biotechnol 20:17-48.

Marini MM, Gomes FCO, Silva CLC, Cadete RM, Badotti F, Oliveira ES, Cardoso CR, Rosa CA (2009) The use of selected starter Saccharomyces cerevisiae strains to produce traditional and industrial cachaça: a comparative study. World J Microbiol Biotechnol 25:235-242.

Meignen B, Onno B, Gélinas P, Infantes M, Guilois S, Cahagnier B (2001). Optimization of sourdough fermentation with 
Lactobacillus brevis and bakers yeast. Food Microbiol 18:238-245.

Nobre TP, Horri J, Alcarde AR (2007). Viabilidade celular de Saccharomyces cerevisiae cultivada em associação com bactérias contaminantes da fermentação alcoólica. Ciência e Tecnologia de Alimentos 27:21-25.

Ortiz-Muñiz B, Carvajal-Zarrabal O, Torrestiana-Sanchez B, Aguilar-Uscanga MG (2010) Kinetic study on ethanol production using Saccharomyces cerevisiae ITV-01 yeast isolated from sugar cane molasses. J Chem Technol Biotechnol 85:1361-1367.

Pereira GVM, Ramos CL, Galvão C, Dias ES, Schwan RF (2010) Use of specific PCR primers to detect three important industrial species of Saccharomyces genus: Saccharomyces cerevisiae, Saccharomyces bayanus and Saccharomyces pastorianus. Lett Appl Microbiol 51:131-137.

Rep M, Krantz M, Thevelein JM, Hohmann S (2000) The Transcriptional Response of Saccharomyces cerevisiae to Osmotic Shock. J Biol Chem 275:8290-8300.

Ribéreau-Gayon P, Glories Y, Maujean A, Dubourdieu D (2006) Alcohols and other volatile compounds. In: Ribéreau-gayon, P., Glories, Y., Maujean, A., Dubourdieu, D. (eds). Handbook of Enology: The Chemistry of Wine and Stabilization and Treatments. John Wiley and Sons Ltd, England, 51-61.
Schwan RF, Mendonça AT, da Silva Jr JJ, Rodrigues V, Wheals AE (2001) Microbiology and physiology of cachaça (aguardente) fermentations. Antonie van Leeuwenhoek 79:89-96.

Stewart GG, Russell I (1981) Yeast flocculation. In: Pollock, J.R.A. (eds). Brewing Science.Academic Presspp, Toronto, 61-92.

Tanghe A, Prior BB, Thevelein JM (2006) Yeast responses to stresses. In: Rosa, C.A., Péter, G. (eds). Biodiversity and ecophysiology of yeasts. Springer-Verlag, Heidelberg, pp 175-195.

Thomas KC, Hynes SH, Ingledew WM (2001). Effect of lactobacilli on yeast growth, viability and batch and semi-continuous alcoholic fermentation of corn mash. J Appl Microbiol 90:819-828.

Valles BS, Bedriñana RP, Queipo AL, Alonso JJM (2008) Screening of cider yeasts for sparkling cider production (Champenoise method). Food Microbiol 25:690-697.

Walker GM (1998) Yeast Physiology and Biotechnology. John Wiley \& Sons Ltd, England.

Wheals AE, Basso LC, Alves DMG, Amorim HV (1999) Fuel ethanol after 25 years. Trends in Biot 17:482-487.

Yokoya F, Oliva-Neto P (2001) Susceptibility of Saccharomyces cerevisiae and lactic acid bacteria from the alcohol industry to several antimicrobial compounds. Braz J Microbiol $32: 10-14$

All the content of the journal, except where otherwise noted, is licensed under a Creative Commons License CC BY-NC. 